\title{
Development and Validation of Teacher Motivation Assessment Scale for Quality Assurance in Universities in Anambra State
}

\author{
Obunadike, J.C. \\ Department of Agriculture/Home Economics Education \\ Michael Okpara University of Agriculture, Umudike, Umuahia, Abia State, Nigeria
}

\section{Doi:10.5901/jesr.2013.v3n6p95}

\begin{abstract}
The main purpose of this study was designed to develop and validate an instrument titled "Teacher Motivation Assessment Scale (TMAS) for quality assurance in universities in Anambra State. Thus, this is an instrumentation study. From literature, five constructs that constitute the major elements of human motivation were identified. The constructs include attitude, reward, commitment, punishment and interest. Initially, a 50-item Motivation Assessment Scale was developed by the researcher for the purpose of face validation and field trial. The initial draft of the instrument was subjected to face validation by 2 specialists in educational research, 5 specialists in educational administration and 2 specialists in measurement and evaluation. Their comments and suggestions were then incorporated in a second draft of the instrument still consisting of 50 items. This was subjected to field trial using fifty lecturers drawn from tertiary institutions in Enugu state. The data from the field trail were subjected to factor analysis to determine the items that were valid and therefore qualified to be included in the instrument for use in the actual study. Based on the factor analysis, 30 items were found to be well loaded. Thus, the draft that was administered to the research subjects consisted of 30 items. Data from the research subjects were analyzed using factor analysis, the Cronbach Alpha and t-test. Out of the 30 items, 8 were dropped. The remaining 22 items were grouped into 9 factors. Out of the 9 factors extracted, only five factors have items substantially loaded on them while four factors did not have up to the minimum loading of four items on them and were therefore ignored (Meredith 1969). The 22 acceptable items were grouped under five motivational constructs with their item loadings. The test of reliability using the 22 items that survival the validation test revealed that the instrument is reliable. The determination of internal consistency of the instrument based on the influence of school location and job experience showed that most of the items of the instrument were stable across school location and job experience. The researcher therefore recommends that the TMAS be used by the management of universities, Deans of faculties and Heads of departments including teachers for quality assurance in universities in Anambra State. It is also recommended that the instrument be used for all categories of tertiary institution for quality assurance irrespective of personality or environmental variables.
\end{abstract}

\section{Introduction}

\subsection{Background of the Study}

Motivation has been conceived from an array of both theoretical and empirical perspectives. It has been viewed from the path-goal orientation (Obi, 1997 Georgapoulos, 1957); from the expectancy view point (Vroom 1964); from the dynamic approach (Maslow, 1965; Alkinson and Birth, 1989) and from the Herzbergs's Motivation - Hygiene perspectives (Enyi, 2000). Although each school of thought convey a divergent view of motivation, all the theoretical and empirical explanations coverage at a unified point where motivation is generally agreed to be the process of arousing, sustaining and regulating the activities of an organism in a given contact. The study of motivation, 
therefore, is primarily concerned with how behaviour is energized, sustained, directed and stopped. The dominant approaches to motivation during the 1940s and 1950s view behaviour as regulated by stimulus-response associative bonds that develop through reinforcement processes (Udokama 1997; Koestner and McClelland, 1994). The psychology of motivation, falling as it does across the road of many different scholarly interests, has long needed a clear-cut definition. It is generally believed that an internal feeling acts behind the human behaviour. This internal feeling or activated force motivates an individual to achieve a goal. In other words, the process of activation, as a result of motivated force, is termed motivation. According to Obi (1997, Azubike, 2013) motivation maybe-seen as the perceptions, methods, activities used by the management for the purpose of providing a climate that is conducive to the satisfaction of the various needs of the employees so that they may become satisfied, dedicated and effective task performer. Therefore, motivation is an embracing factor in an employee's development to accomplish personal as well as organizational goals.

Herberg's Motivation-Hygiene theory makes a distance between two sets of job factors. One set is related to the actual doing of the job, the job content, or the intrinsic aspect of the job (Anyanwu, 2002: Enyi, 2000). These factors are called motivators and they include: achievement, recognition, works itself, responsibility, and advancement. The other set of job factors is related to the environmental setting or extrinsic factors of the job. These factors are termed hygiene and they include: policy and administration, interpersonal relations, supervision, salary, working conditions, status, security, possibility of growth and personal life. All these factors, both intrinsic and extrinsic determine, to a great extent the functioning of a classroom teacher on the job.

Teacher motivation, according to Diyoke (2005) is an individual phenomenon. By this he means teachers' emotional and mental reactions to his work, which affects the amount of work he does. Teachers want security and comfortable living, pleasant working conditions and a sense of belonging, treatment, a sense of achievement, a feeling of importance and a part of policy formulation.

This trend, therefore, shifted the attention of educators to teachers job orientation. While emphasis on strategies for enhancing teacher effectiveness on the job continues to dominate in current literature and while also there seem to be a convergence of ideas on the role of motivation in teacher effectiveness, the exact quantification of teacher motivational states has been merely speculative. In the same vein, it is possible that no current theory of motivation has been able to explain, and more importantly predict the behaviour of an individual consistently. Available theories, at best, could only predict group behaviour with a fair amount of errors at some levels of probability (Arvey and Neel 2004).

While weaving fanciful propositions, replete with exotic hypothetical constructs to explain past behaviour most of the existing theories tend to be versions of an approach, which argues that two opposing forces inhere in an individual's life and interact to motivate that person. None has been able to quantify, in an individual the amount of force towards equilibrium and the extent of drive the individual has to seek change or disequilibrium. One would expect that a teacher's motivational behaviour towards his job would be influenced by a number of factors. Such factors include the location of the school where he teachers and the length of the teacher's professional experience. These factors have been extensively studied in the developed countries where there is limited literature on work that has been done on these two factors with regard to how they influence teachers motivation in carrying out their jobs. For instance in his own work Murdock (1994) found that the location of a school whether in an urban or rural area did not make any significant difference in levels of teachers motivation on the job. Murdock's study is interesting because he used a large secondary school sample drawn from across the United Kingdom. The influence of location of a school on motivation was found not to be significant in a study reported by Akpan (2007).

In a national survey on the role of professional experience as a factor of motivation on the job, carried out in Nigeria by Onyedinma (1989), it was found that the professional experience of a 
teacher was not a significant factor that influence teacher motivation on the job. From the foregoing, it is clear that more studies are needed in the area of teacher motivation especially in developing countries including Nigeria. It is possible that one reason why such studies have not been carried out in developing countries like Nigeria is because of paucity of valid and reliable instrument for measuring motivation of teachers. Yet, such studies are important for their contributions in understanding and improving the role of teachers in our educational systems.

The perennial problem of teacher poor work orientation sympathized by truancy, dereliction of duty, apathy, lateness to duty (Ibeakor, 1997, Edochie 2008) tend to raise a number of issues which bother on the implementability and survival of the new educational programmes being implemented by the Nigeria Federal Government. Although educators (Afolabi, 2009; Iheonumekwu, Anyatonwu \& Eze 2012, Haruna, 2007) have linked these problems to internal disposition of teachers emanating from poor work conditions, their arguments appear not to have been substantiated. In the same vien, in as much as it would not be said that poor teacher job orientation stems from the poor motivation of teachers it could also not be established with a fair amount of certainty that teachers are adequately motivated. This is as a result of the paucity of instruments for measuring teachers' level of motivation. Not even the application of the Structural Equation Model (Anastasi, and Urbina 2008) or the Alkinson's (1984) Schema Approach quantity the extent of teacher motivation.

As such, a major problem in motivation studies is its measurability. In response to this problem, this study is faced with the task of developing and validating an instrument, which could be generally applied with a fair amount of certainty in the measurement of motivational status of teachers.

\subsection{Research Question}

The following research questions guided this study.

1. How valid are the items of the TMAS in terms of their factor loadings?

2. What is the reliability coefficient of the Teacher Motivation Assessment Scale (TMAS)?

3. What influence has school location on the Motivation of teachers?

4. What influence has teacher job experience on the motivation of teachers?

\section{Methodology}

The population of the study comprised all the lecturers in Faculties of Education in the three universities in Anambra state. The universities include Nnamdi Azikiwe University, Awka (Federal); Anambra State University, Uli (State) and the Madonna University, Okija (Private). The sample of the study comprised 60 lecturers purposively selected from Faculties of Education in the three universities. Twenty (20) lecturers were selected from each university Faculty of Education. This study adopted an instrumentation research design. According to Mehrens and Lehman (1991), an instrumentation research is the type which aims at developing and certifying the efficacy of an instrument for the measurement of a given behaviour or construct.

The instrument developed in this study was the Teacher Motivation Assessment Scale (TMAS). The initial draft copy of TMAS has fifty items. The draft is a 4- point modified likert type scale divided into two sections. Section ' $A$ ' was designed to seek background information of the respondents. Section " $B$ " was designed to seek information based on motivation constructs. The rating scale options are strongly Agree $(S A=4)$; Agree $(A=3)$; Disagree $(D=2)$; and Strongly Agree $(S D=1)$. The instrument was duly validated by experts in educational research and educational administration. The reliability was assessed using factor analytic approach. The researcher employed the direct delivery technique in the administration of the instrument to the research subjects. The principal factor solution, Cronback Alpha and mean scores were employed in the data analysis. 


\section{Results}

\subsection{Research Question 1}

How valid are the items of the Teacher Motivation Assessment Scale (TMAS) in terms of their factor loading?

Responses of the teachers who were used for this study were subjected to data reduction procedures (ie. Factor analysis) using principal component analysis and factor matrix. For the TMAS the normal varimax method of rotation was done with reference to the principal factor solution for the thirty items. Summary of the varimax rotated factor loading for the thirty items/variable is shows in the appendix.

Summary of data revealed that out of the nine factors extracted, only five factors (factors $1,2,3,4$ and 5) have items substantially loaded on them. Out of the 30 items used for this study, twenty-two items had at least a minimum loading of 0.35 . Four factors, $(6,7,8$ and 9) did not have enough items substantially loaded on them. On the other hand, items 9 and 15 were not loaded on any factor while six items (items 2, 3, 12, 13, 20 and 24) were loaded on more than one factor and were considered factorially impure. These items were discarded. Factors 1,2,3,4 and 5 were accepted as valid. According to Meredith (1969) the minimum number of items for accepting a factor is four. The five factors and the associated twenty-two items considered to be factorially valid are specified in table 1 (see appendix).

\subsection{Research Question 2}

What is the reliability coefficient of the teacher motivation assessment scale?

After the data reduction using the varimax method of rotation, it was found that two items were not loaded. The items were 9 and 15. However items 2, 3, 12, 13, 20 and 24 were loaded on more than one factor. Therefore the eight items (2, 3, 9, 12, 15, 13, 20 and 24) were considered factorially impure. The eight items were discarded. Thereafter the remaining twenty-two items were subjected to test of internal consistency, using the Cronbach Alpha. The summary is shown in table 2 at the appendix.

\subsection{Research Question 3}

What influence has school location on motivation of teachers?

The result of the influence of location on the motivation of teachers is shown in table 3. (see the appendix).

Teachers in rural areas agreed with the views on items 7, 16, 17, 18, 19 and 21 . Teachers in urban and rural areas recorded the lowest means responses of 1.57 and 1.39 respectively on item 30 of TMAS. This item tried to find out whether teachers are given assistance in solving their personal problems. On the other hand, both teachers in the urban and rural areas recorded their highest mean responses of 3.50 and 3.67 respectively on item 21 of TMAS, which was on whether basic duties are made available to teachers.

\subsection{Research Question 4}

What influence has teachers' job experience on the motivation of teachers?

The result of the influence of job experience on the motivation of teachers is shown in table 4. (see the appendix). The result in Table 4 shows that both experienced and less experienced teachers disagreed with the views on items I, 4, 5, 6, 10, 11, 14, 22, 23, 25, 26, 27, 28, 29, and 30 while the agreed with the views on items 7, 17, 18, 19 and 21 . The experienced and less experienced teachers recoded the lowest mean of 1.1 and 1.49 respectively in item 
Similarly, the experienced and less experienced teachers recorded their highest mean 3.55 and 3.59 respectively in item 21 of the TMAS, which found out whether basic allowances accruing from extra duties are made available to teachers.

\subsection{Summary of Finding}

The analysis of the data revealed the following findings:

Out of the 30 items of the TMAS subjected to factor analysis, 22 items met the requirements for acceptance as valid items. The remaining eight items were dropped because they were not up to the cut-off or minimum acceptable value of 0.35 . They are items $2,3,9,12,13,15,20$ and 24. While items $2,3,12,13,20$ and 24 were considered factorially complex or impure because they were loaded on more than one factor. Items 9 and 15 did not attain a minimum loading of 0.35 on any factor. The 22 valid items were distributed along the five factors, which explains motivational constructs. The 22 - items of the TMAS that emerged as acceptable items substantially high internal consistency of 0.74 , indicating that the instrument is a reliable measure of motivation among teachers.

Furthermore, school location affect the responses on TMAS. Since urban and rural responses differed significantly much in the same vein, length of experience of the teacher affected their responses on TMAS since experienced and less experienced responses were found to vary significantly.

\subsection{Discussion of Findings}

The initial 30-item Teacher Motivation Assessment Scale (TMAS) was subjected to factor analysis using the varimax rotated factor loading. As shown earlier, nine factors were extracted by the PC but only five factors had items substantially loaded on them. Item 2, 3, 9, 12, 13, 15, 20 and 24 were dropped completely from the second draft of the teacher motivation assessment scale. Specifically, item 2 was loaded on factors 1 and 7 while items 3 and 12 were loaded on factors 1 and 6 . Also item 13 was loaded on factors 6 and 7 while items 20 and 24 were loaded on factors 1 and 8,6 and 8 respectively. Since they appeared in more than one factor, they were described as factorial complex. 1 items 9 and 15 were not loaded on any factor and were also dropped. Meredith (1969) recommended that a loading of 0.35 should be the minimum for accepting any item. The five constructs representing the five factors in which the items were loaded are attitude, commitment, reward, punishment and interest. Factor 1 has to do with motivation resulting from attitude to job. Factor 2 has to do with items that addresses the dimension of motivation that has to do with commitment. Factor 3 reveals that aspect of motivation that relates to reward. Factor 4 has to do with the construct that pertains to punishment. While factor 5 linked with interest in the job.

During factors analysis, eight items did not meet the criteria for accepting items as valid in the instrument. These items are 2, 3, 9, 12, 13, 15, 20 and 20. Items 2, 3, 12, 13, 20 and 24 were dropped from the instrument because they were loaded on more than one factor. Item 9 and 15 were dropped because they were not adequately loaded on any factor. The surviving twenty-two items were subjected to a test of internal consistency using Crombach alpha. Reliability is referred to the degree of consistency of a measuring instrument (Mehren and Lehman 1991). Since the instrument is of the Likert-type, the Cronbach test of internal consistency was considered most. The summary of the test revealed alpha of 0.74 . This indicates that the instrument has high interitem consistency ad therefore reliable.

Research question 3 reflected particularly on school location. Thus, the influence of school location on the motivation of teachers. Subsequently, Table 3 showed mean responses. The surviving 22 items for both urban and rural recorded the lowed mean response of 1.57 and 1.39 respectively on item 30 of TMAS. Also both teachers in urban and rural disagreed with the views on 
items 1, 4, 5, 6, 10, 11, 14, 22, 23, 25, 26, 28, 29 and 30 while the teachers in urban areas disagreed with the view on item 8 . In addition, both teachers in urban and rural agreed with the views on items $7,16,17,18,19$, and 21 . Furthermore, both teachers in the urban and rural areas recorded their highest mean response of 3.50 and 3.67 respectively on item 21 of the TMAS. Thus, school location has significant influence on the scores of teacher motivation.

However, the results agree with earlier findings of researchers like Ogbodo (1993) and Okeke (1994). These researchers observed that teachers in rural areas and those in urban areas are not equally motivated. Due to environmental circumstances, the interest, commitment, attitudes, reward and punishment of these teachers vary. Although, researchers have already established remarkable differences in line with their differences in 15 items as against 6 that agreed, it must be appreciated that for some aspects of their job, there must be convergence especially when the construct measured are not environmentally dependent. Murdock (1994), Obunadike (2008) noted that the location of a school whether in urban or rural did not make any significant difference in levels of teacher motivation.

The influence of job experience on the Teacher Motivation Assessment Scale was also explored. Summary of data analysis presented in table 4 . Table 4 showed that both experienced and less experienced teachers disagreed with the view on items $1,4,5,6,10,11,14,22,23,25$, $26,27,28,29$ and 30, while they agreed with the views on items 7, 17, 18, 19 and 21. Both experienced and less experienced teachers recorded the lowest mean of 1.51 and 1.49 respectively on item 30 of the TMAS. Nevertheless, the experienced and less experienced teachers recorded their highest mean of 3.55 and 3.59 respectively on item 21 of the TMAS. Obi (1997) noted that interest in the teaching profession develops with teaching profession develops with time or declines with time. His argument is that, in as much as teaching as a profession is concerned, interest in the job is time dependent.

Out of the 30 items that were used for the actual study, only 22 items survived. These 22 items were grouped according to their motivation constructs. Already five motivation constructs were identified from the literature. These constructs are: Attitude, Commitment, Reward, Punishment and Interest.

\subsubsection{Attitude Items}

1. Adequate instructional facilities are always made available to enhance our job performance.

6. There is a fair consideration for all teachers in assignment of responsibilities.

19. The government and school authority, usually stimulate and encourage teachers to greater work efficiency.

26. Conditions of service for teachers are stream-lined to enhance their performance.

\subsubsection{Commitment Items}

10. The authority provides enough incentives to challenge teacher productivity

16. Teachers are allowed to express their feeling about their jobs.

17. There is approval for teachers who apply for in-service training

30. Teachers are usually given assistance in solving their personal problems.

\subsubsection{Reward Items}

4. Adequate leisure activities/programmes are enjoyed by teachers.

7. Teachers receive adequate commendation for jobs well done

14. Teachers who go for further studies are recognized by the authority through instant promotion or higher rank when they successfully complete their studies

22. Teachres are promoted regularly without prejudice. 
23. Teachers are paid monies to enable them attend seminars and workshops.

\subsubsection{Punishment Items}

11. Usually, there is poor human relationship between teachers and the school authority.

21. Basic allowances accruing from extra duties are not made available to teachers.

25. Erring teachers are not included in school activities that yield money to participants.

27. Teachers are derived compensations that are due to them.

28. Teachers are denied up-to-date information about their jobs.

\subsubsection{Interest Items}

5. The authority often uses constructive criticism in correcting defualting teachers.

8. Teachers' social status are often compromised

18. Teachers enjoy adequate welfare scheme

29. There is a special package for teachers whose students excel in examinations.

\section{Conclusion}

The following conclusions are drawn from this study

a. Twenty-two item Teacher Motivation Assessment Scale was developed from the initial draft of 30 items. Five factors were found to explain teacher motivation and the represent the following constructs; interest, attitude, reward, punishment and commitment.

b. The inter-item consistency analysis of the instrument using the Cronbach procedure, reveals that the TMAS has high internal consistency of 0.7 as such reliable.

c. The instrument is stable with respect to school location and job experience. The responses on the instruments did not deviate much from the initial findings about the variable and the constructs on which the items were loaded.

\subsection{Educational Implications of the Study}

This study has interesting implication not only for teaching and learning but also for quality assurance in universities. The study has developed a valid and reliable instrument, which measures teachers motivation. The implication is that the problem of how best to measure teacher level of motivation can be addressed. This will go a long way in resolving the quality assurance questions in our universities. Most universities find it difficult to assess the motivational status of their teachers because they have no suitable measuring instrument. With this instrument available, the motivational status of teachers could be assessed from time to time in Anambra State and Nigeria in general for quality assurance in the educational programmees.

University administrators can now determine when there is need to motivate their subordinate so as to enhance productivity. This newly developed instrument going by their psychometric attributes and conference with established theories and research findings has been shown to exhibit relative stability across location and job experience. This implies that from now onward teacher motivation can be most effectively assessed without expectations of bias and the quality of our university products will be high.

\subsection{Recommendations}

Based on the findings of this study, the researcher made the following recommendations

a. The Teacher Motivation Assessment Scale should be used by universities administrators in assessing the teacher motivation level. 
b. Since the instrument does not discriminate across school location and job experience, it is recommended that the instrument be used for all categories of teachers, especially in for quality assurance.

\section{References}

Afolabi, P. (2009). The Plight of the Nigerian Secondary School Teachers. Educational Research Reports, XII, NO. 4

Akpan, D. (2007) Motivation in Teaching. Journal of child Development 37, pp. 57-59

Anastasi, A and Urbina, S. (2008) Psychological testing. New Jersey: Prentice Hall.

Anyanwu, A.C. (2002). Influence of Negative Reinforcement on Students Task Performance. Unpublished B. Ed Project, University of Nigeria.

Arvey, R.D. and Neel, C.W. (2004). Testing Expectancy Theory Prediction Using Behaviourally based Measures of Motivational Efforts for Engineers". Journal of Vocational Behaviour 4._299-30.

Atkinson, J.W. (1984). An Introduction to motivation. New Jersey: Van Nostrand.

Atkinson, J.W, and Birch, D. (1989). The dynamics of action. New York: Wiley.

Azubuike, N.O. (2013) Conditions of Service for Teaching/Teachers in Nigeria. Perspectives in Teacher Education ( $2^{\text {nd }}$ Edition) Onitsha West and Solomon. Publishing Coy Ltd.

Diyoke, U. (2005). Educational management A system approach. Lagos: Literalised publications Ltd.

Edochie, F. (2008). The Ideal Headmaster: A Myth or Reality. Journal of Research in Teaching and Learning, 29, 2.

Enyi, D. (2000), Herzberg's Motivation-Hygiene Theory: Application and implication for the Nigerian Educational Administrators. Journal of Empirical Studies in Psychological and Education. 39.

Georgopolous, B. (1957). Path goal approach to productivity. Journal of Applied Psychology 47, 13.

Haruna, A. (2007). Motivation and schooling. Kaduna: Newbold Book Co.

I beakor, S. (1997). General overview of the school administrator. Owerri: Totan Book Publishers.

Iheonunekwu, S, Anyatonwu, N \& Eze, O. R. (2012) Employees' Attitude Towards Momentary and nonmomentary incentives in public enterprises. The state of Education in Nigeria. Onitsha West and Solomon Publishing Coy Ltd. 438 - 471.

Koestner R. and McClelland D.C. (1994). Perspective on competence motivation. In L.A. Perrin (Ed) $A$ handbook of personality theory and research. New York: The Guilford Press.

Maslow, A.H. (1965). A theory of Human Motivation. Psychological review. P 370-379.

Mehrens A.W. and Lehman J. (2010). Measurement and evaluation in education and psychology. New York: Wiley.

Meredith, G.N. (1969). Dimensions of Facility of Course Evaluation. Journal of Psychology, 38, pp 210221.

Murdock, C. (1994) Children and Learning. New York: Wiley.

Obi, E. (1997) Motivation and Organizational Behaviour: In A.N. Ndu, L.O. Ocho and B.S. Okeke (Eds), Dynamics of educational administration and management. The Nigerian perspective. Onitsha. Meks Publishers Ltd. P 110-120.

Obunadike, J.C. (2008) Effective motivations of Primary School teachers for the attainment of Millenium development goals. Education in the information Age. Global challenges and Enhancement strategies. Proceeding of faculty of Education Conference UNN 476 - 488.

Ogbodo R.U. (1993). Conditions of staff personnel motivation. Journal of Education 13, 1-8.

Okeke, B.S. (1994). A Handbook on educational administration. Owerrie: New African Pub. Co. Ltd.

Onyedinma, E. (1989). Unresolved issues of teachers Welfare Packages. Journal of Education. Vol 8, pp 41-51.

Udokama, N. (1997) Issues in the 6-3-3-4 school System Revisited. Journal of Internal Education. 31, 2. Vroom, V. (1984). Work and motivation. New York. Wiley 
Table 1. The Five Motivation Constructs with the Five Factors and their Factor Loadings.

\begin{tabular}{|c|c|c|c|c|}
\hline Constructs & Factors & Items & Item Loading & Communality \\
\hline \multirow{4}{*}{ Attitude } & \multirow{4}{*}{1} & 1 & .47961 & .61680 \\
\hline & & 6 & .42470 & .45474 \\
\hline & & 19 & .63994 & 61792 \\
\hline & & 29 & 61091 & .55239 \\
\hline \multirow{4}{*}{ Commitment } & \multirow{4}{*}{2} & 10 & .44710 & .59702 \\
\hline & & 16 & .35292 & .49276 \\
\hline & & 17 & .64077 & .61660 \\
\hline & & 30 & .63189 & .55794 \\
\hline \multirow{5}{*}{ Reward } & \multirow{5}{*}{3} & 4 & .44235 & .51268 \\
\hline & & 7 & .48175 & .51961 \\
\hline & & 14 & .47028 & .57383 \\
\hline & & 22 & .35036 & .85317 \\
\hline & & 23 & .62108 & .59015 \\
\hline \multirow{5}{*}{ Punishment } & \multirow{5}{*}{4} & 11 & .45453 & .51922 \\
\hline & & 21 & .38389 & .83866 \\
\hline & & 25 & .43046 & .66742 \\
\hline & & 27 & .38977 & .52826 \\
\hline & & 28 & .45923 & .60647 \\
\hline \multirow{4}{*}{ Interest } & \multirow{4}{*}{5} & 5 & .51803 & .42588 \\
\hline & & 8 & .49291 & .40799 \\
\hline & & 18 & .64507 & .66724 \\
\hline & & 29 & .61091 & .50924 \\
\hline
\end{tabular}

Table 2. Cronbach Alpha Test on 22 items of TMAS, for its internal consistency

\begin{tabular}{|c|c|c|c|c|c|c|}
\hline \multirow{2}{*}{ Statistics for scale } & Mean & Variance & Std Dev. & N of variables & & \\
& 49.9822 & 57.3761 & 7.5747 & 22 & & \\
\hline \multirow{2}{*}{ Item means } & Mean & Minimum & Maximum & Range & Max/min & Variance \\
& 2.2720 & 1.3911 & 3.6704 & 2.2793 & 2.6386 & 0.3836 \\
\hline Item & Mean & Minimum & Maximum & Range & Max/min & Variance \\
Variances & 1.3763 & 0.3518 & 6.0725 & 5.7207 & 17.2598 & 2.4875 \\
\hline Inter-item & Mean & Minimum & Maximum & Range & Max/min & Variance \\
Correlations & 0.0647 & -0.4362 & 0.4938 & 0.9299 & -1.1320 & 0.0304 \\
\hline \multicolumn{7}{|c|}{ Reliability coefficients for 22 items: } \\
\hline
\end{tabular}

Alpha $=0.7385$ Standardized item alpha $=0.6036$

Table 3. Mean of the Responses of Teachers in Urban and Rural on the 22 Items of the TAMS

\begin{tabular}{|c|c|c|c|}
\hline S/NO & I tems & \multicolumn{2}{|c|}{ Rural } \\
\hline & & Mean $(\mathrm{x})$ & Means $(\mathrm{x})$ \\
\hline 1 & 1 & 85 & 2.03 \\
\hline 2 & 4 & 84 & 1.74 \\
\hline 3 & 5 & 94 & 2.17 \\
\hline 4 & 6 & 85 & 2.49 \\
\hline 5 & 7 & 1.07 & 2.60 \\
\hline 6 & 8 & 85 & 2.63 \\
\hline 7 & 11 & 83 & 1.89 \\
\hline 8 & 11 & 88 & 1.76 \\
\hline 9 & 14 & 96 & 1.71 \\
\hline
\end{tabular}




\begin{tabular}{|c|c|c|c|}
\hline 10 & 16 & 87 & 2.79 \\
\hline 11 & 17 & 88 & 3.07 \\
\hline 12 & 18 & 86 & 3.41 \\
\hline 13 & 19 & 88 & 3.03 \\
\hline 14 & 21 & 82 & 3.67 \\
\hline 15 & 22 & 1.93 & 2.22 \\
\hline 16 & 23 & 82 & 1.79 \\
\hline 17 & 25 & 89 & 1.77 \\
\hline 18 & 26 & 90 & 1.76 \\
\hline 19 & 27 & 95 & 2.34 \\
\hline 20 & 28 & 86 & 1.68 \\
\hline 21 & 29 & 87 & 1.39 \\
\hline 22 & 30 & 75 & \\
\hline
\end{tabular}

Grand Mean for Urban $=2.31 ;$ Grand Mean for Rural $=2.26$

Table 4. Mean of the Responses of Teachers Experienced and Less Experienced on the 22 items of the TAMS

\begin{tabular}{|c|c|c|c|}
\hline S/NO & I tems & Experienced & Less Experienced \\
\hline & & Mean $(x)$ & Means $(x)$ \\
\hline 1 & 1 & 1.92 & 2.34 \\
\hline 2 & 4 & 1.88 & 1.94 \\
\hline 3 & 5 & 2.27 & 2.22 \\
\hline 4 & 6 & 2.38 & 2.54 \\
\hline 5 & 7 & 2.61 & 2.56 \\
\hline 6 & 8 & 2.39 & 1.66 \\
\hline 7 & 11 & 1.82 & 1.98 \\
\hline 8 & 11 & 1.83 & 1.94 \\
\hline 9 & 14 & 1.67 & 1.91 \\
\hline 10 & 16 & 2.81 & 2.59 \\
\hline 11 & 17 & 2.97 & 2.82 \\
\hline 12 & 18 & 3.29 & 3.09 \\
\hline 13 & 19 & 3.12 & 2.81 \\
\hline 14 & 21 & 3.55 & 3.58 \\
\hline 15 & 22 & 2.43 & 2.04 \\
\hline 16 & 23 & 1.87 & 1.94 \\
\hline 17 & 25 & 1.79 & 2.01 \\
\hline 18 & 26 & 1.90 & 1.98 \\
\hline 19 & 27 & 2.07 & 2.26 \\
\hline 20 & 28 & 2.37 & 2.31 \\
\hline 21 & 29 & 1.84 & 1.92 \\
\hline 22 & 30 & 1.51 & 1.48 \\
\hline
\end{tabular}

Grand Mean for Experienced $=2.31 ;$ Grand Mean for Less Experienced $=2.26$. 